\title{
Septation of the single ventricle: Revisited
}

Renee E. Margossian, MD

David Solowiejczyk, MD ${ }^{\mathrm{a}}$

Francois Bourlon, MD $^{\mathrm{c}}$

Howard Apfel, MD ${ }^{\mathrm{a}}$

Welton M. Gersony, MD

Allan J. Hordof, MD

Jan Quaegebeur, MD ${ }^{\mathrm{b}, \mathrm{c}}$

From the New York Presbyterian HospitalColumbia University, the Divisions of Pediatric Cardiology $\mathrm{y}^{\mathrm{a}}$ and Pediatric Cardiothoracic Surgery, ${ }^{\mathrm{b}}$ New York, NY, and the Cardiothoracic Centre of Monaco. ${ }^{\mathrm{c}}$

Received for publication March 30, 2001; revisions requested June 14, 2001; revisions received Oct 15, 2001; accepted for publication Nov 19, 2001

Address for reprints: Renee Margossian, MD, Department of Cardiology, Boston Children's Hospital, 300 Longwood Ave, Boston,MA02115(E-mail:reneem@cardio. tch.harvard.edu).

J Thorac Cardiovasc Surg 2002;124:442-7

Copyright $(\odot) 2002$ by The American Association for Thoracic Surgery

0022-5223/2002 $\$ 35.00+0 \quad \mathbf{1 2 / 1 / 1 2 2 2 9 9}$

doi: $10.1067 / \mathrm{mtc} .2002 .122299$
Background: Septation of a single ventricle into 2 functioning ventricles can provide an alternative to the Fontan operation. However, early experiences with septation reported unacceptable morbidity and mortality. The present study selected only those patients with large volume-overloaded hearts, 2 well-functioning atrioventricular valves, and an absence of severe outlet obstruction. Early and intermediate outcomes are evaluated.

Methods and Results: Between June 1990 and March 1999, 11 patients underwent septation in 1 or 2 stages. Diagnoses of the patients included double-inlet left ventricle in 9, double-inlet right ventricle in 1 patient, and indeterminate ventricle in 1 patient. Five had L-transposition and 3 had D-transposition of the great arteries. Six had septation as 1 stage, 5 as planned 2-stage operations ( $2 / 5$ completed). The median age for septation in 1 stage was 2.1 years (range 4 months to 5.8 years); for 2 stages, the median age was 7.2 months (range 3 to 14 months). Median follow-up time was 2.3 years. Eight of 11 patients survived (73\%), with 2 early deaths and 1 late death. Seven of the 8 survivors have undergone complete septation (5 as single stage, 2 as 2 stages). Complications included surgically induced complete atrioventricular block in 1 patient and significant residual ventricular septal defects in another. Qualitatively, left ventricular function by echocardiography is normal in all patients, whereas right ventricular function is mildly decreased in 1 patient. All patients are clinically well.

Conclusion: The septation procedure for single ventricle hearts may be a reasonable alternative to the Fontan operation in selected patients.

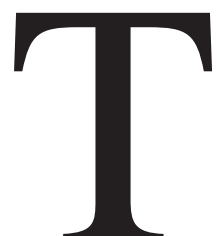

he first successful ventricular septation was performed in 1956 by Kirklin. ${ }^{1}$ However, early experience with this procedure resulted in unacceptable morbidity and mortality. ${ }^{1-4}$ Possible risk factors for poor outcome included random selection of patients, the necessity of a ventriculotomy for the surgical approach, and loose patch placement resulting in inflow or outflow obstruction. 5,6 The Fontan operation is currently considered to be the surgical procedure of choice for patients with single ventricle heart disease. However, since septation could provide a 4-chambered heart as opposed to the Fontan operation, recent advances in surgical techniques have renewed our interest in septation for carefully selected patients. Patients chosen for septation in this study included those with 2 well-developed and normally functioning atrioventricular (AV) valves; a large, volume-overloaded ventricle to optimize right and left ventricular size after septation; and an absence of severe subaortic obstruction or ventricular hypertrophy.

The original approach to septation was to use a ventriculotomy to create a septum with a single patch. Whereas septation in 1 stage has been performed for more than 40 years, the 2-stage approach was proposed in 1984 by Ebert. ${ }^{7}$ He used 2 separate patches in the initial stage. One patch was placed in the apex between the papillary 
TABLE 1. Summary of clinical data for 11 patients undergoing septation

\begin{tabular}{|c|c|c|c|c|c|c|c|}
\hline $\begin{array}{l}\text { Patient } \\
\text { No. }\end{array}$ & Diagnosis & $\begin{array}{l}\text { Age at first } \\
\text { septation } \\
\text { procedure } \\
\text { (y) }\end{array}$ & $\begin{array}{c}\text { Prior } \\
\text { procedures }\end{array}$ & $\begin{array}{c}\text { One- or two-stage } \\
\text { procedure }\end{array}$ & $\begin{array}{l}\text { Associated } \\
\text { procedures }\end{array}$ & Complications & Results \\
\hline 1 & DILV, L-TGA & 1.2 & None & Two (complete) & $\begin{array}{l}\text { PAB (first stage), } \\
\text { PAB removal } \\
\text { (second stage) }\end{array}$ & None & Survived \\
\hline 2 & DILV, NRGA, PS & 2.5 & None & One & $\begin{array}{l}\text { Pulmonary } \\
\text { valvotomy }\end{array}$ & None & Survived \\
\hline 3 & DILV, NRGA & 0.33 & None & One & None & None & Survived \\
\hline 4 & $\begin{array}{l}\text { Indeterminate } \\
\text { ventricle, D-TGA }\end{array}$ & 1.1 & $\begin{array}{l}\text { PAB, atrial } \\
\text { septectomy } \\
\times 2\end{array}$ & One & ASO, PAB removal & $\begin{array}{l}\text { Influenza B } \\
\text { pneumonia }\end{array}$ & Died \\
\hline 5 & DILV, L-TGA & 1.7 & PAB & One & PAB removal & None & Survived \\
\hline 6 & DIRV, D-TGA & 0.33 & None & Two (complete) & $\begin{array}{l}\text { Atrial septectomy, } \\
\text { PAB (first stage), } \\
\text { ASO, PAB } \\
\text { removal (second } \\
\text { stage) }\end{array}$ & $\begin{array}{l}\text { Residual VSDs } \\
\text { after second } \\
\text { stage }\end{array}$ & Survived \\
\hline 7 & DILV, NRGA & 5.8 & PAB & One & PAB removal & None & Survived \\
\hline 8 & DILV, L-TGA, PS & 0.83 & None & $\begin{array}{l}\text { Two (awaiting } \\
\text { completion) }\end{array}$ & None & None & Survived \\
\hline 9 & $\begin{array}{l}\text { DILV, D-TGA, CoA, } \\
\text { submitral narrowing }\end{array}$ & 0.25 & None & $\begin{array}{l}\text { Two (died after } \\
\text { first stage) }\end{array}$ & $\begin{array}{l}\text { ASO, CoA repair, } \\
\text { mitral } \\
\text { valvuloplasty, PAB }\end{array}$ & $\begin{array}{l}\text { Low cardiac } \\
\text { output }\end{array}$ & Died \\
\hline 10 & DILV, L-TGA, CoA & 4.3 & PAB, CoA repair & One & $\begin{array}{l}\text { BVF enlargement, } \\
\text { PAB removal }\end{array}$ & $\begin{array}{l}\text { Postop } \\
\text { hemorrhage, } \\
\text { Complete AVB }\end{array}$ & Survived \\
\hline 11 & DILV, L-TGA, CoA & 0.63 & $\begin{array}{l}\text { PAB, CoA } \\
\text { repair, } \mathrm{PM} \\
\text { placement }\end{array}$ & $\begin{array}{l}\text { Two (died after } \\
\text { first stage) }\end{array}$ & $\begin{array}{l}\text { BVF enlargement, } \\
\text { PAB removal }\end{array}$ & Fungal sepsis & Died \\
\hline
\end{tabular}

ASO, Arterial switch operation; $A V B$, atrioventricular block; $B V F$, bulboventricular foramen; $C o A$, coarctation of the aorta; DILV, double-inlet left ventricle; $D I R V$, double-inlet right ventricle; D-TGA, D-transposition of the great arteries; L-TGA, L-transposition of the great arteries; NRGA, normally related great arteries; $P A B$, pulmonary artery banding; $P S$, pulmonary stenosis; $V S D$, Ventricular septal defect.

muscles and another sutured between the aortic and pulmonary anuli, thus leaving open the center section of the neoseptum. Because there was no pressure gradient across the septum, the patches stiffened and healed to the endocardium. Fewer sutures needed to be placed, thus limiting the possible damage to the conduction system. Since patients are left with an unrestrictive ventricular septal defect (VSD) after the first stage, a pulmonary artery band was placed if one was not already in place. In the present study, the Ebert 2-stage technique was used for the younger and smaller patients.

\section{Methods}

\section{Patients}

Between June 1990 and March 1999, 11 patients underwent ventricular septation by a single surgeon at 2 medical centers (Table 1). Eight patients underwent surgery at Columbia-Presbyterian Medical Center, and 3 underwent surgery at the Cardiothoracic Centre of Monaco. There were 8 boys and 3 girls. Six patients had a 1 -stage procedure; 5 had a 2 -stage procedure. One additional patient went to the operating room for a septation procedure, but had a Fontan operation instead, because of previously unappreciated straddling of the tricuspid valve chordal apparatus.

The ventricular morphology included a double-inlet left ventricle (DILV) in 9 patients, double-inlet right ventricle (DIRV) in 1 patient, and indeterminate ventricle in 1 patient (Table 1). Of the 9 patients with DILV, 5 had L-transposition of the great arteries (L-TGA), 3 had normally related great arteries (NRGA), and 1 had D-transposition of the great arteries (D-TGA). The patients with DIRV and an indeterminate ventricle both had D-TGA. Two of the patients had mildly restrictive bulboventricular foramina, each with pressure gradients of $10 \mathrm{~mm} \mathrm{Hg}$ from the left ventricle to the aorta as measured by cardiac catheterization. Additional anomalies of cardiac anatomy included coarctation of the aorta in 3 patients, pulmonary stenosis in 2 , and mitral valve obstruction in 1 . It is important to note that none of the patients had contraindications to the Fontan procedure.

The median age for patients undergoing a 1-stage procedure was 2.1 years (range 4 months to 5.8 years); the median weight was $11.3 \mathrm{~kg}$ (range $4.0-19.6 \mathrm{~kg}$ ). For the 5 infants undergoing a planned 2-stage repair, the median age at the first stage was 7.2 
TABLE 2. Procedures performed concurrently with septation

\begin{tabular}{lc}
\hline & No. \\
\hline PA band removal & 5 \\
Arterial switch & 3 \\
PA band & 3 \\
BVF enlargement & 2 \\
Coarctation repair & 1 \\
Pulmonary valvotomy & 1 \\
Mitral valvuloplasty & 1 \\
Atrial septectomy & 1
\end{tabular}

$B V F$, Bulboventricular foramen; $P A$, pulmonary artery.

months (range 3-14 months) with a median weight of $6.3 \mathrm{~kg}$ (range $3.8-9.0 \mathrm{~kg}$ ). Two patients have had septation completed by means of the 2-stage approach. The ages at completion were 11.5 months and 22 months; the patients weighed 6.2 and $10 \mathrm{~kg}$ at the time of the second stage. Two of the 1-stage patients were relatively young at the time of the operation, 1 being 4 months old and the other 1 year old. Another underwent a 2-stage approach at the relatively late age of 15 months old. These 3 patients underwent surgery early in our experience, before our management strategy was further defined.

Five of the 11 patients underwent surgery before a septation procedure, 4 of the 1 -stage patients and 1 of the 2 -stage patients. These included pulmonary artery banding in all 5 , coarctation repair in 2 and pacemaker insertion for intermittent complete heart block in 1 patient with $\{\mathrm{S}, \mathrm{L}, \mathrm{L}\}$ morphology. Additional procedures at the time of septation were required in 7 of 11 patients (Table 2). The operative times for the patients are summarized in Table 3. These times reflect the septation component of the operation, as well as additional surgical repairs.

\section{Surgical Techniques}

The operations were performed by means of cardiopulmonary bypass with moderate hypothermia in 7 patients and deep hypothermia in 4. Myocardial protection was achieved through cardioplegia administered every 30 minutes of aortic crossclamp time. The operation was done in either a 1- or 2-stage technique. The first parts of both methods are identical. In all patients a transatrial approach through the right-sided AV valve was used, providing complete exposure for septation. In 1 patient, after bulboventricular outflow tract enlargement, the left ventricular outflow tract was assessed for adequacy by inspection through the aortic valve. The initial part of the operation involves full delineation of the papillary systems to verify the feasibility of septation. Specifically, the chordal apparatus of both AV valves is inspected to determine their exact attachment to be certain they straddle neither the outlet chamber nor the contralateral ventricle. If portions of the chordal insertions attach to the same papillary muscle, they are assessed for the possibility of splitting the muscle to allow the insertion of the septal patch. The ventricle is then divided with a polytetrafluoroethylene* (PTFE) patch that is fashioned to provide an exact fit

* Gore-Tex patch; registered trademark of W. L. Gore \& Associates, Inc, Flagstaff, Ariz.
TABLE 3. Operative times

\begin{tabular}{lcc}
\hline & Median (min) & Range (min) \\
\hline Bypass time & & \\
One stage & 135 & $75-233$ \\
First of 2 stages & 124 & $93-193$ \\
Second of 2 stages & 154 & $97-210$ \\
Crossclamp time & & \\
One stage & 84 & $69-150$ \\
First of 2 stages & 90 & $45-130$ \\
Second of 2 stages & 75 & $45-105$ \\
\hline
\end{tabular}

(Figure 1). Any laxity in the patch can lead to inflow and/or outflow obstruction in the postoperative period.

The patch is first attached at the apex of the heart between the papillary muscles. By means of a running suture, the suture line is then brought up between the $2 \mathrm{AV}$ valve anuli and then between the outlet valves. The relationship among the papillary muscles, the AV valve anuli, and the 2 outlet valves determines patch placement. There is little discretion left to the surgeon in these areas. However, anteriorly the patch can be manipulated to adjust the relative volumes of the right and left ventricles. Here, the patch is placed in such a way that the left ventricular volume is slightly larger than the right. Full attachment of the patch completes the procedure for the 1-stage technique.

The 2-stage procedure is begun in the same manner. Once the patch is in place, an unrestrictive VSD is created. The creation of the VSD allows for further ventricular growth in smaller infants. If the pulmonary vascular bed is not already protected by a pulmonary artery band or native pulmonary stenosis, a band is placed at the first stage. The VSD is then closed during the final stage with a second PTFE patch. The second stage is generally done 6 to 12 months after the first.

\section{Results}

\section{Perioperative}

Figure 2 summarizes the outcome for the 11 patients in the series. Of the 6 patients who underwent septation as a 1 -stage procedure, 5 are alive and well. There was 1 early death in this group. Among the 5 patients who had a 2-stage procedure, 2 have undergone completion. There was 1 early and 1 late death in this group. One patient is awaiting the final stage of completion.

The overall mortality in this series was 3 of 11 (27\%), 2 deaths occurring early and 1 late. One of the 2 early deaths occurred in a 13-month-old child with an indeterminate ventricular morphology and D-TGA (patient 4, Table 1) who previously had undergone balloon atrial septostomy, pulmonary artery banding, and blade atrial septostomy. He died 5 days postoperatively of influenza B pneumonia. The second early death (patient 9) occurred in a 3-month-old infant who had no prior procedures. His anatomy included DILV, D-TGA, mitral valve obstruction, and a coarctation. He had the most extensive surgery in this series of patients, including partial septation, arterial switch, mitral valvuloplasty, 
coarctation repair, and pulmonary artery banding. He died of low cardiac output and poor ventricular performance 5 hours after the operation. The late death in this series (patient 11, Table 1) occurred in an infant with DILV and L-TGA who had previously undergone pulmonary artery banding and coarctation repair and subsequently had a pacemaker inserted for intermittent complete heart block. He had a prolonged postoperative course after partial septation and bulboventricular foramen enlargement. His recovery was complicated by fungal sepsis, and he was discharged from the hospital 2.5 months later. He died of complications of fungal sepsis 5 months after the operation.

For the surviving patients, the median intensive care unit stay was 6 days with a range of 2 to 165 days. The median hospital stay was 16 days with a range of 10 to 194 days. The outlying patient who was hospitalized for 194 days (patient 6) was the only patient in the series with a DIRV who required 2 surgical attempts at closure of residual VSDs. The VSDs were ultimately closed with a clamshell device.

Among the 8 survivors, 6 were in sinus rhythm after septation. Patient 10 had complete heart block in the perioperative period. His operation included a 1-stage septation, pulmonary artery band removal, and enlargement of the bulboventricular foramen. He had a pacemaker placed 8 days after the opertion. In patient 4 , heart block developed 7.5 months after the first stage of septation but before the second stage.

\section{Follow-up}

The median follow-up time was 2.3 years with a range of 2 months to 8 years. All of the 8 survivors are asymptomatic; 6 of the 8 are receiving no cardiac medications. The 2 patients who continue to receive medications include patient 6 with a DIRV, and patient 10, whose operation was the most recent.

Six patients have remained in sinus rhythm throughout their clinical course. Patients 10 and 1 remain in heart block. Ventricular function was assessed by 2-dimensional echocardiography for qualitative evaluation of free wall motion and thickening. All patients have good neo-left ventricular function; patient 6 , the 1 patient with a septated DIRV, has mildly diminished neo-right ventricular function. No patient has more that mild AV valve regurgitation by echocardiography. The 7 fully septated patients have tiny, restrictive patch margin leaks seen by color Doppler ultrasonography only. Two patients have mild pulmonary stenosis, with maximum Doppler instantaneous gradients of $20 \mathrm{~mm} \mathrm{Hg}$ in both. One of these 2 also has mild branch pulmonary artery stenosis, with gradients of $20 \mathrm{~mm} \mathrm{Hg}$ to the right and $25 \mathrm{~mm}$ $\mathrm{Hg}$ to the left. No patient has left ventricular outflow tract obstruction.

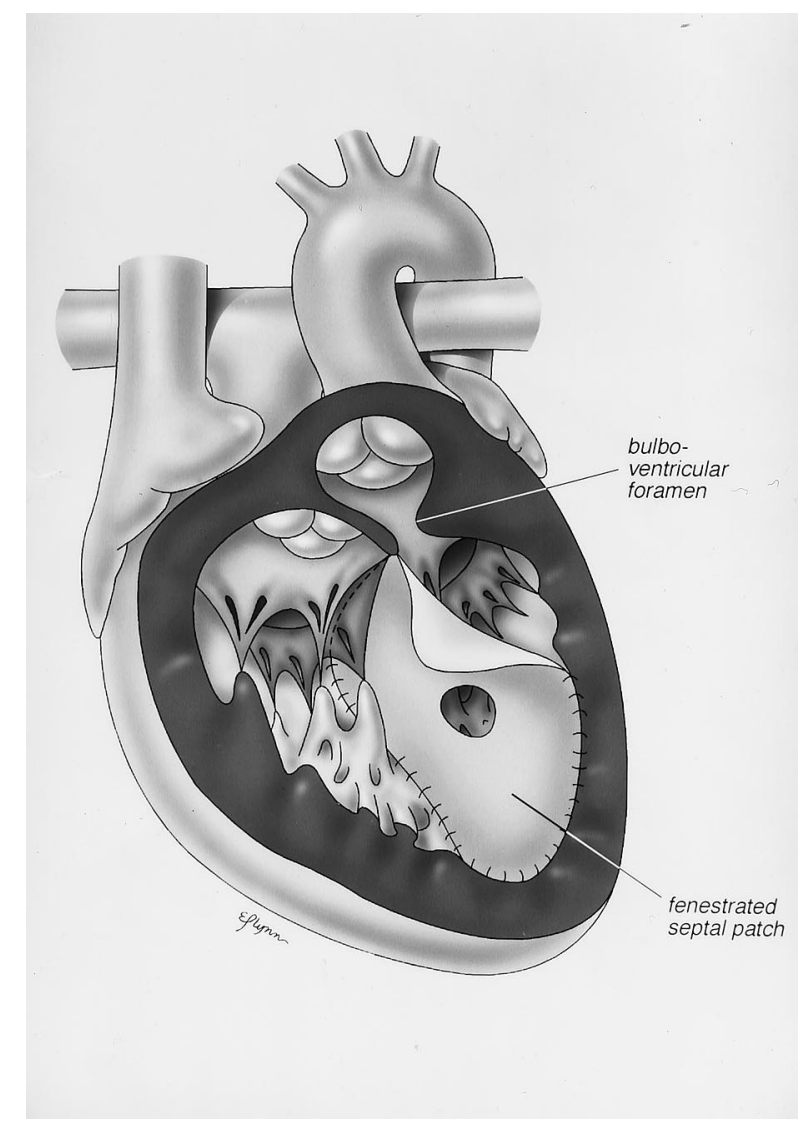

Figure 1. The ventricle is divided with a fenestrated PTFE patch first attached at the apex, between the papillary muscles. It is then attached between the $2 \mathrm{AV}$ valve anuli, then between the outlet valves.

\section{Discussion}

Most centers use the Fontan operation as the sole surgical option for single ventricles. Given the widely known late complications associated with the Fontan procedure, we hypothesized that in some patients the ventricular septation procedure could provide a reasonable alternative, resulting in biventricular physiology.

Septation of the single ventricle became a surgical option after the first reported success by Kirklin ${ }^{1}$ in 1956. Although Edie and associates ${ }^{8}$ reported early success with septation, surgical mortality in most early series ranged from $36 \%$ to $47 \% .2,3,9$ Since that time few reports have demonstrated significant improvement in outcome. The major early drawbacks to septation were the need for a ventriculotomy, loose noncontractile patches that resulted in outflow obstruction, surgically induced heart block, and paradoxical patch motion. In response, Doty, Schieken, and Lauer ${ }^{10}$ described a transatrial approach in 1979, eliminating the need for a ventriculotomy. Later, Ebert ${ }^{7}$ recommended a 2-stage approach in 1984. This technique limited the incidence of surgically induced heart block, allowed tighter patch place- 


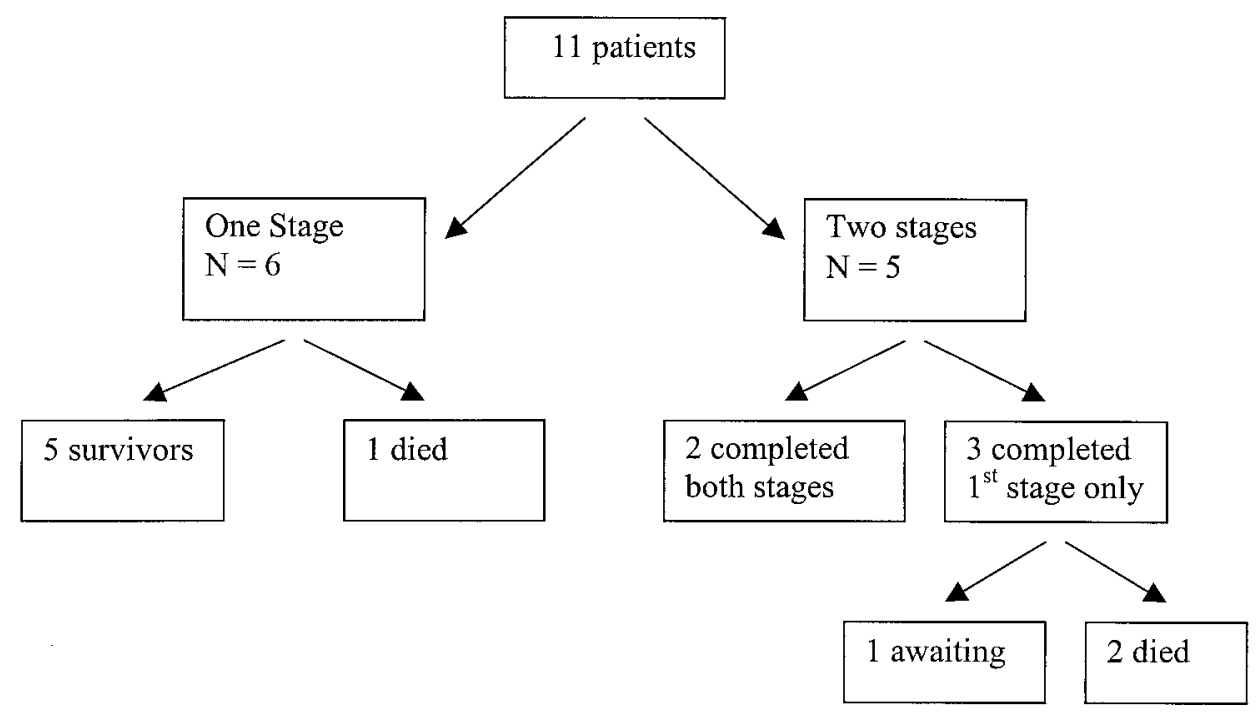

Figure 2. Summary of surgical outcomes.

ment to eliminate outflow obstruction, and permitted earlier definitive surgery in young infants. Finally, the problem of a noncontractile prosthetic septum compromising left ventricular pump function necessitating greater end-diastolic volume was addressed by asymmetric placement of the neoseptum so that the left ventricle was slightly larger than the right ventricle. ${ }^{11}$ With these surgical innovations and increased experience with septation, one center has reported recent success with septation. ${ }^{12}$

To improve outcomes in the present series still further, we sought to add to the aforementioned refinements in patient selection. McGoon and colleagues ${ }^{1}$ reported poor outcome to be associated with abnormal AV valve function and McKay and coworkers ${ }^{3}$ described small ventricular size and bulboventricular foramen outlet obstruction as incremental risk factors for hospital death. Nagashima and colleagues ${ }^{13}$ related ventricular hypertrophy to be a surgical risk factor. Thus, based on the experience discussed in these early reports, patients selected for septation in this series included only those with 2 well-developed and normally functioning AV valves; a large, volume-overloaded ventricle; and an absence of severe subaortic obstruction and ventricular hypertrophy.

The overall mortality for patients in this series was $27 \%$ (3/11), which although superior to the previous septation series, is still worse than that of comparable patients undergoing Fontan palliation. This may indicate that patient selection needs to be limited even further, as the patients who died generally required more extensive operations (eg, arterial switch operation in 2 patients) than those who survived. The need for greater selectivity was also suggested by the need for multiple reinterventions in the 1 patient in this series with a morphologically right ventricle to close residual VSDs.

Placing an artificial septum in a small child raises the question of growth. Performing the first of a 2-stage septation early in life should result in a favorable patch-tomyocardial mass relationship as the patient grows. The absolute area of the septum that is patch material after completed septation is relatively smaller in the older infant. Long-term AV valve function in a heart whose septal length is fixed, late cardiac rhythm, and ventricular function are also unknown factors.

The surviving patients in this series have had good clinical outcome and display qualitatively good ventricular function. However, because of the irregular geometry of the surgically created ventricles and lack of landmarks such as regularly spaced papillary muscles, a noninvasive method for formal assessment of ejection fraction and volume has not been established. All patients also have good AV valve function and have not experienced rhythm disturbances during early and intermediate follow-up. Despite extensive surgery in the region of the conduction system, only 1 patient had perioperative heart block, although late heart block developed in 1 patient and another had a pacemaker placed before septation. Longer follow-up, including formal exercise testing and rhythm monitoring, will be needed to determine whether this group will demonstrate superior long-term outcomes compared with patients undergoing conventional Fontan operations, as would be expected with biventricular physiology.

Our results demonstrate that with careful patient selection, ventricular septation in patients with a single ventricle heart can be accomplished with good results. On the basis of 
our experience, certain features appear to lay the foundations for better outcome: a morphologically left ventricle, 2 well-developed and normally functioning AV valves, a large, volume-overloaded ventricle, and an absence of severe subaortic obstruction and ventricular hypertrophy. Complex procedures such as arterial switch operations during the same operation should be avoided. It is likely that criteria for septation may be further modified and expanded in the future, as experience and new surgical techniques evolve.

\section{References}

1. McGoon DC, Danielson GK, Ritter DG, Wallace, RB, Maloney JD, Marcelletti C. Correction of the single ventricle heart having two atrioventricular valves. J Thorac Cardiovasc Surg. 1977;74:218-26.

2. Feldt RH, Mair DD, Danielson GK, Wallace RB, McGoon DC. Current status of the septation procedure for single ventricle hearts. J Thorac Cardiovasc Surg. 1981;82:93-7.

3. McKay R, Pacifico AD, Blackstone EH, Kirklin JW, Bargeron LM Septation of the single ventricle heart with left anterior subaortic outflow chamber. J Thorac Cardiovasc Surg. 1982;84:77-87.

4. Franklin RCG, Spiegelhalter DJ, Filho RR, Macartney FJ, Anderson RH, Rigby ML, et al. Double-inlet ventricle presenting in infancy. III.
Outcome and potential for definitive repair. $J$ Thorac Cardiovasc Surg. 1991;101:924-34.

5. Stellin G, Mazzucco A, Bortolotti U, Faggian G, Livi U, Angelini A, et al. Late failure of double-inlet left ventricle septation: treatment by orthotopic heart transplantation. Ann Thorac Surg. 1989;48:577-8.

6. Arai T, Sakakibara S, Ando M, Takao A. Intracardiac repair for single or common ventricle, creation of a straight artificial septum. Singapore Med J. 1973;14:187-9.

7. Ebert PA. Staged partitioning of single ventricle. J Thorac Cardiovasc Surg. 1984;88:908-13.

8. Edie RN, Ellis K, Gersony WM, Krongrad E, Bowman FO, Malm JR. Surgical repair of single ventricle. J Thorac Cardiovasc Surg. 1973; 66:350-60.

9. Steffanelli G, Kirklin JW, Naftel DC, Blackstone EH, Pacifico AD, Kirklin JK, et al. Early and intermediate (10 year) results of surgery for single ventricle atrioventricular connection ("single ventricle"). Am J Cardiol. 1984;54:811-21.

10. Doty DB, Schieken RM, Lauer RM. Septation of the single ventricle heart, transatrial approach. J Thorac Cardiovasc Surg. 1979;78:42330.

11. Nakazawa M, Aotusuka J, Imai Y, Kurosawa H, Fukuchi S, Satomi G, et al. Ventricular volume characteristics in double inlet left ventricle before and after septation. Circulation. 1990;81:1537-43.

12. Imai Y, Hashino S, Koh YS, Nakazawa M, Momma K. Ventricular septation procedure for single ventricle connection of left ventricular type. Semin Thorac Cardiovasc Surg. 1994;6:48-55.

13. Nagashima M, Imai Y, Takanashi Y, Hoshino S, Seo K, Terada M, et al. Ventricular hypertrophy as a risk factor in ventricular septation for double-inlet left ventricle. Ann Thorac Surg. 1997;64:730-4.

\section{Online-www.aats.org}

Now you can get The Journal of Thoracic and Cardiovascular Surgery online. The Journal online brings you faster delivery time, easy searching of current and back issues, links to PubMed, AATS, WTSA, and other important sites, and more. Visit the Journal online today.

\section{Receive tables of contents by e-mail}

To receive the tables of contents by e-mail, sign up through our Web site at http://www.mosby.com/jtcvs

Choose E-mail Notification

Simply type your e-mail address in the box and click the Subscribe button. Alternatively, you may send an e-mail message to majordomo@mosby.com. Leave the subject line blank and type the following as the body of your message: subscribe jtcvs_toc

You will receive an e-mail to confirm that you have been added to the mailing list.

Note that TOC e-mails will be sent out when a new issue is posted to the Web site. 